\title{
Clean-up of cereal extracts for gas chromatography-tandem quadrupole mass spectrometry pesticide residues analysis using primary secondary amine and C18
}

\author{
Herrmann, Susan Strange; Poulsen, Mette Erecius
}

Published in:

Journal of Chromatography A

Link to article, DOI:

10.1016/j.chroma.2015.10.086

Publication date:

2015

Document Version

Peer reviewed version

Link back to DTU Orbit

Citation (APA):

Herrmann, S. S., \& Poulsen, M. E. (2015). Clean-up of cereal extracts for gas chromatography-tandem quadrupole mass spectrometry pesticide residues analysis using primary secondary amine and C18. Journal of Chromatography A, 1423, 47-53. https://doi.org/10.1016/j.chroma.2015.10.086

\section{General rights}

Copyright and moral rights for the publications made accessible in the public portal are retained by the authors and/or other copyright owners and it is a condition of accessing publications that users recognise and abide by the legal requirements associated with these rights.

- Users may download and print one copy of any publication from the public portal for the purpose of private study or research.

- You may not further distribute the material or use it for any profit-making activity or commercial gain

- You may freely distribute the URL identifying the publication in the public portal 

residues analysis using primary secondary amine and C18

Herrmann, Susan S. and Poulsen*, Mette E.

National Food Institute, Technical University of Denmark, Mørkhøj Bygade 19, DK-2860 Søborg,

${ }^{*}$ Corresponding author. $\mathrm{Tel}+4535887000$

Email address: sher@food.dtu.dk (S. S. Herrmann)

\section{Abstract}

The level of co-extracted matrix in wheat and oat extracts obtained by the QuEChERS method (EN 15662) is high and the occurrence of free fatty acids generates a major matrix peak in TIC chromatograms (rt. 13-22 $\mathrm{min}$ ). Matrix can compromise the analytical performance in pesticide analysis using GC-MS/MS. In order to reduce the amount and the effects of matrix we tested the effect of using six different amounts of primary secondary amine (PSA) $(0,25,50,100,150$ and $200 \mathrm{mg} / \mathrm{ml}$ extract) with and without the addition of six different amounts of $\mathrm{C} 18(0,25,50,100,150$ and $200 \mathrm{mg} / \mathrm{ml}$ extract) in the dispersive solid phase extraction (dSPE) procedure. dSPE clean-up using $25 \mathrm{mg} / \mathrm{ml}$ extract significantly reduced the major matrix peak observed for wheat extracts. Higher amounts of PSA reduced the analytical response for iprodione and malathion. For oat extract 50-150 mg PSA/ml extract was needed to obtain equally low intensity of the matrix peak. For oat the analytical responses of the target pesticides generally increased with increasing amount of PSA. C18 had no significant effect on the intensity of the major matrix peaks and even resulted in lower analytical responses for several of the target pesticides. Based on the present study it is concluded that the optimal dSPE clean-up procedure employs $25 \mathrm{mg} \mathrm{PSA} / \mathrm{ml}$ extract for wheat and $150 \mathrm{mg} \mathrm{PSA} / \mathrm{ml}$ extract for oat.

\section{Introduction}

About 1000 pesticides are available on the world market and residues of all of these may potentially occur in our foods including cereals. Multi-residue methods are a necessity in order to monitor and control residues of as many of these pesticides in our food as possible. A generic extraction method allowing efficient extraction of a wide range of analytes is needed for such multi-methods. The Quick, Easy, Cheap, Effective, Rugged, and Safe (QuEChERS) method published at the CEN method EN 15662 [1] is a generic extraction method, which has become widely used for the extraction of pesticide residues from food matrices and has also been introduced in our laboratory. During the development of the QuEChERS method several factors, as choice of extraction solvent, amount and types of partitioning conditions, extraction time and $\mathrm{pH}$ etc., were tested and optimised with the aim to obtain satisfactory recovery for a wide range of pesticides, that vary greatly in regard to their physical/chemical characteristic [2]. A drawback of such a generic extraction method is however, that also natural constituents of the samples are extracted, i.e. co-extracted matrix.

Occurrence of co-extracted matrix is generally unwanted because it can result in inaccurate quantification and reduced ruggedness of a method. The matrix can e.g. interact with the analyte or active sites in the inlet or gas chromatographic (GC) column to change the instrumental response or it selves produce an instrumental response. By using matrix matched external calibration for quantification, some of the matrix 
effects can be compensated for. However, by this approach the amount of matrix introduced into the analytical system is also increased, and this may result in the need for more frequent instrument maintenance and thereby also more instrument down-time. Matrix induced ion suppression can also compromise the method performance in LC-MS/MS analysis. Though, because of the improved sensitivity of triple quadrupole instruments, dilution of the extract has become common practice for the reduction or elimination of matrix effects in LC-MS/MS analysis. In GC analysis, the presence of matrix can act as analyte protectants and thereby increase the instrumental response for some pesticides and consequently also the sensitivity of the method. Examples of pesticides that give higher analytical responses in the presence of matrix are azoxystrobin, phosmet, malathion, iprodion [3], acephate, dimethoate and omethoate [4]. Thus in GC the approach of diluting the samples until the matrix effects become insignificant, may not be a recommended approach, because some analytes simply never get to the mass spectrometer in the absence of matrix. Though, in cereal extracts obtained by the QuEChERS method, employing dispersive Solid Phase extraction (dSPE), clean-up with $25 \mathrm{mg}$ primary secondary amine (PSA) per ml extract, the amount of matrix is so high that it increases the requirement for instrument maintenance and/or reduces the ruggedness of the method. Thus for cereal extracts a major portion of the co-extracted matrix is not removed by dSPE with 25 mg PSA per ml extract, and a reduction of the amount of co-extracted matrix will be beneficial.

By analysing QuEChERS extracts of cereals by GC-MS in scan mode we have found, that a major peak elute at rt. 13-22 min. Examples of these major matrix peaks, in wheat and oat extract, are presented in the total ion chromatograms (TIC) in Figure 1. These major matrix peaks, have by investigations at our laboratory (unpublished data), but also by Mastovska, Dorweiler, Lehotay, Wegscheid, \& Szpylka, 2010 [5], been found to consist of various fatty acids and primarily linoleic acid. According to data in The National Food Institute's Food Composition Databank (www.foodcomp.dk) wheat and oat have a fat content of 20 $\mathrm{g} / \mathrm{kg}$ and $65 \mathrm{~g} / \mathrm{kg}$, respectively. The fatty acids accounting for the largest fraction of this fat content is linoleic acid (44-52\%), oleic acid (25-35\%) and palmitic acids (15-24\%) [6]. In order not to compromise the generic nature of the QuEChERS method a clean-up procedure, that specifically removes the free fatty acids, would be optimal. However to our knowledge such a procedure is not available. PSA is known to bind compounds containing carboxylic acid groups and therefore a likely candidate for the removal or reduction of the fatty acids in cereal extract. PSA will in many cases also bind acidic pesticides. PSA clean-up may therefore not always be amenable to analysis of pesticides by liquid chromatography. Mastovska et al. 2010 [5] found, that the major matrix peak of maize was significantly reduced by increasing the amount of PSA used in the dSPE, from $10 \mathrm{mg}$ PSA per gram sample to $60 \mathrm{mg}$ PSA per gram sample and also introducing $20 \mathrm{mg}$ octadecyl (C18) sorbent per gram sample. Rice, rye and maize contain more fat than wheat but less than oat. Oat and wheat therefore represents the lower and upper extreme regarding fat content for the most common types of cereal. For fatty foods as milk, egg and avocado $\mathrm{C} 18$ has also been shown to reduce the amount of co-extracted matrix [7]. Thus both PSA and C18 may reduce the amount of co-extracted matrix in cereal extracts.

Thus, the amount of interfering matrix in cereal extracts obtained by our present method may be further reduced, if the amount of PSA used in the dSPE step is optimised and by also introducing C18. More extensive clean-up may, however, also remove the target analytes resulting in low recoveries. So it is often a compromise which needs to be found, i.e. an optimised clean-up procedure, by which enough of the interfering matrix is removed, in order to have a robust method, but still allows for acceptable recovery of the target analytes. Because PSA efficiently bind acids it is not feasible for analysis of acidic pesticides [8].

The aim of the present work was therefore to study whether the dSPE employed for dSPE clean-up of wheat and oat extracts obtained by the QuEChERS method could be optimised by adjusting the amount of PSA employed and by introducing $\mathrm{C} 18$ in the procedure. Proficiency test material was used, i.e. wheat EU proficiency test C2 (EUPT-C2) [9] and oat (EUPT-C3) [10] containing incurred and spiked pesticides. The effect of the defined test dSPE procedure, were evaluated by determining the intensity of matrix peaks in TIC 
chromatograms and the analytical response obtained for the test analytes, in comparison to those obtained using no clean-up or the clean-up procedure according to the QuEChERS method, EN 15662 procedure.

\section{Experimental}

\subsection{Chemicals}

The pesticide standards (all purity $>96 \%$ ) were purchased from Dr. Ehrenstorfer (Augsburg, Germany). The acetonitrile (HPLC Grade S) was purchased from Rathburn Chemicals (Walkerburn, UK) and acetic acid and ammonium acetate were from Merck (Darmstadt, Germany). The magnesium sulphate was purchased from J.T.Baker, Aventor Performance Materials B.V (Center Valley, PA 18034, USA), sodium chloride from Merck \& Co. (Whitehouse Station, NJ, USA), sodium citrate dehydrate and sodium citrate sesquihydrate from Sigma Aldrich Chemie GmbH (Taufkirchen, Germany) and the clean/up sorbents PSA from Agilent Technologies (Santa Clara, CA 95051, USA), and C18 from International Sorbent Technology Ltd. (Gengoed Mid Glam, UK). Pesticide standard stock solutions of $1 \mathrm{mg} / \mathrm{ml}$ were prepared in toluene and stored at $-18{ }^{\circ} \mathrm{C}$ in ampoules with argon atmosphere. A standard mixture of $10 \mathrm{mg} / \mathrm{ml}$ in acetonitrile was prepared from these stock solutions. Working solutions were prepared by dilution of this standard mixture and finally matching them 1:1 with extract of wheat and oat not containing pesticide residues obtaining a concentration range of 0.0015 to $0.05 \mathrm{mg} / \mathrm{ml}$. The extracts used for matrix matching were obtained by the extraction and clean-up procedure described in section 3.2 as our standard procedure.

\subsection{Extraction and clean-up procedure}

The point of departure was the extraction and clean-up procedure employed as standard procedure for cereals at our laboratory, which is in accordance with the CEN method EN 15662. In brief, $5.0 \mathrm{~g}$ of milled cereal was added $10 \mathrm{ml}$ of cold water and immediately extracted with $15.0 \mathrm{ml}$ of acetonitrile by shaking the tube $1 \mathrm{~min}$ by hand. To aid the extraction a ceramic homogenizer was included. After this $6.0 \mathrm{~g}$ magnesium sulphate, $1.5 \mathrm{~g}$ sodium chloride, $1.5 \mathrm{~g}$ sodium citrate dihydrate and $0.75 \mathrm{~g}$ sodium citrate sesquihydrate was added. After $1 \mathrm{~min}$ of shaking by hand and centrifugation for $10 \mathrm{~min}$, at $4300 \mathrm{~g} 8 \mathrm{ml}$ of the supernatant was transferred to a clean tube and stored at $-80^{\circ} \mathrm{C}$ for minimum 1 hour. The extracts were then thawed and when still very cold centrifuged at $4300 \mathrm{~g}$ for $5 \mathrm{~min}$ (freezing out step). One $\mathrm{ml}$ of the supernatant was cleaned by dSPE by transferring it to a centrifuge tube containing $25 \mathrm{mg}$ PSA and $150 \mathrm{mg}$ magnesium sulphate (i.e. $25 \mathrm{mg} \mathrm{PSA} / \mathrm{ml}$ extract). After shaking by hand for $30 \mathrm{~s}$ and centrifugation for $5 \mathrm{~min}$ at $4300 \mathrm{~g}$ the extract was analysed by GC-MS/MS, thus, only GC amendable pesticides were included in the study.

The test material used was wheat and oat reference material from EUPT-C2 and EUPT-C3, respectively. Both of these reference materials contain incurred as well as spiked pesticides. The test materials were produced by milling of kernels in a centrifugal mill with $1 \mathrm{~mm}$ sieve.

The study consisted of three experiments, in which the effect of different amounts of PSA and C18 used during dSPE clean-up of the extract obtained after the freezing out step was evaluated (Table 1). The evaluation parameters were the intensity of the matrix peaks in TIC chromatograms (Figure 1) as well as the analytical result obtained by analysis in Multiple Reaction Monitoring (MRM) mode for the pesticides in the test material (Figure 3). In experiment 1 six levels of PSA were tested $(0-200 \mathrm{mg} / \mathrm{ml})$. In experiment 2 were the effect of combining the six levels of PSA $(0-200 \mathrm{mg} / \mathrm{ml})$ with equal amounts of C18 $(0-200 \mathrm{mg} / \mathrm{ml})$ studied. In experiment 3 were the effect of using a fixed amount of PSA of $150 \mathrm{mg} / \mathrm{ml}$ in combination with six levels of $\mathrm{C} 18(0-200 \mathrm{mg} / \mathrm{ml})$ tested. All experiments were performed as double determinations.

\subsection{Chromatographic separation and detection}


The analysis was performed on a Quattro Micro Tandem GC-MS/MS (Waters, USA). The system consisted of a PAL-GC Auto sampler, an Agilent GC $6890 \mathrm{~N}$ and a Quattro Micro Tandem mass spectrometer. The GC was equipped with a Gerstel PTV injector for large volume and $4 \mu$ was injected. The injector program started with an initial temperature of $30^{\circ} \mathrm{C}$ for $0.8 \mathrm{~min}$ followed by a ramp of $480{ }^{\circ} \mathrm{C} / \mathrm{min}$ to $290^{\circ} \mathrm{C}$, held for 2 min. Finally, the temperature was raised with $720^{\circ} \mathrm{C} / \mathrm{min}$ to 330 to clean the injector. The GC oven programme started with an initial temperature of $60^{\circ} \mathrm{C}$ held for $3 \mathrm{~min}$, followed by a ramp of $30{ }^{\circ} \mathrm{C} / \mathrm{min}$ to 180 ${ }^{\circ} \mathrm{C}$, held for $0.8 \mathrm{~min}$, then $5{ }^{\circ} \mathrm{C} / \mathrm{min}$ to $280^{\circ} \mathrm{C}$, held for $3 \mathrm{~min}$. To clean the column, the temperature was raised with $40^{\circ} \mathrm{C} / \mathrm{min}$ to $300^{\circ} \mathrm{C}$ for $10 \mathrm{~min}$ and $120^{\circ} \mathrm{C} / \mathrm{min}$ to $310^{\circ} \mathrm{C}$ for $1 \mathrm{~min}$. Chromatographic separation was performed on a RESTEK, Rxiß-5ms, $30 \mathrm{~m}$., $0.25 \mathrm{mmID}, 0.25 \mu \mathrm{m}$ df column with a constant flow of 1.3 $\mathrm{ml} / \mathrm{min}$ of helium as carrier gas. The temperature of the transfer line and ion source was set at $250^{\circ} \mathrm{C}$ and $180^{\circ} \mathrm{C}$, respectively. The mass spectrometer was operated in the electronic ionization mode $(\mathrm{El}, 70 \mathrm{eV})$. Analysis in scan mode was employed to obtain TIC chromatograms for the determination of the intensities of the matrix peaks. MRM was used to perform mass spectrometric quantification of the pesticides. The employed MRM transitions, retention times and collision energies are listed in Table 2. Quantification was based on bracketing calibration curves of five matrix matched standard solutions, covering the relevant concentration range.

\section{Results and discussion}

The aim of the present work was to study whether the dSPE employed for clean-up of cereals extracts could be optimised by adjusting the amount of PSA employed and by introducing C18 in the procedure. The aim of such an optimization was to: 1) reduce the amount of matrix loaded into the system without significantly compromising the analytical response and thereby the sensitivity, but also 2) to increase the ruggedness of the method for pesticides co-eluting with the major matrix peak, both in term of variability of retention times and response.

\subsection{Reduction of major matrix peaks}

A major matrix peak was observed in TIC chromatograms of cereals extracts at rt. 13-22 min. The components accounting for this matrix peak, most likely contributes to the increased need of instrument maintenance, when analyzing cereal extracts, as well as to the reduced method ruggedness for some pesticides eluting in the same region. TIC chromatograms, obtained for wheat and oat extracts, cleaned by procedure I, II, III, IV and VI in the 3 experiments, are presented in Figure 1. Results for clean-up procedure $V$ is not shown in order to simplify the figure and because these did not deviate from the observed pattern for the other experiments. The intensity of the matrix peak (rt. 13-22 min) for oat (Figure 1b) is significantly higher than for wheat (Figure 1a). This is in good agreement with the facts that the lipid content of oat is approximately three times higher than of wheat.

Increasing amounts of PSA (0-200 mg/ml extract) reduced the major matrix peak (rt. 13-22 min) in the wheat extracts (Figure 1a). Just $25 \mathrm{PSA} \mathrm{mg} / \mathrm{ml}$ extract was sufficient for significant reduction. For the oat extracts on the other hand, $150 \mathrm{PSA} \mathrm{mg} / \mathrm{ml}$ extract were needed in order to obtain correspondingly low matrix peak intensity (Figure 1b). Using more than $150 \mathrm{mg} \mathrm{PSA} / \mathrm{ml}$ extract for the clean-up did not further reduce the matrix peak. Addition of C18 $(0-200 \mathrm{mg} / \mathrm{ml}$ extract) in equal amounts to PSA $(0-200 \mathrm{mg} / \mathrm{ml}$ extract) did not reduce the intensity of the matrix peak further, neither for the wheat nor the oat extracts (Figure 1c and 1d).

However, C18 $(25 \mathrm{mg} / \mathrm{ml})$ seemed to reduce the amount of co-extracted compounds in the wheat extract eluting after $30 \mathrm{~min}$ or later (data not shown). This effect was not observed for the oat extract. Compounds eluting this late are expected to include phytosterols. Generally, oat has a low content of phytosterols and this low level may be the reason for not observing the same effect as for wheat. Hou et al. 2013 also found that $\mathrm{C} 18(50 \mathrm{mg} / \mathrm{ml}$ extract) only have limited effect on the amount of co-extracted matrix from rice [11]. PSA would be expected to be a more efficient sorbent for the relatively polar free fatty acids (FFA), than C18 would be. C18 is a more efficiently sorbent for non-polar lipids. 
Based on these results $150 \mathrm{mg}$ PSA/ml extract was chosen as a fixed factor and combined with increasing amounts of $\mathrm{C} 18$ for clean-up in Experiment 3 . As can be seen from figure $1 \mathrm{e}$ and $1 \mathrm{f}$ this experiment confirmed that including C18 in the dSPE clean-up has virtually no effect on the amount of co-extracted matrix in the region where the target pesticides elute for neither wheat nor oat extract (rt. 13-22 min).

\subsection{Effect on analytical result}

Clean-up may, as mentioned, not only result in removal of the co-extracted matrix but may also result in loss of analytes. Thus in order to evaluate the applicability of the different clean-up procedures (Table 1), the effect on the analytical response of the target analytes also needs to be evaluated accordingly.

The levels of the incurred and spiked pesticide residues in the test material were in the range of 0.01-1.23 $\mathrm{mg} / \mathrm{kg}$. The assigned values are listed in Table 2. The spike procedure is described in Poulsen et al. (2009) [9].

Increasing amounts of PSA, for clean-up of wheat extracts, resulted in lower levels of iprodione and malathion (Figure 2a). The levels of the other pesticides in the wheat samples were reduced by less than $20 \%$ even when using $200 \mathrm{mg}$ PSA. For oat, increasing levels of PSA in the clean-up procedure resulted in increasing responses for fenbuconazole and metconazole (Figure $2 b$ ). The levels of malathion and fludioxonil seemed to be decreased by PSA. However, the response for malathion seems to approach that of the uncleaned extract when using 150 or $200 \mathrm{mg} \mathrm{PSA} / \mathrm{ml}$. However, the content of malation was very low (assigned value of $0.011 \mathrm{mg} / \mathrm{kg}$, Table 2) and the relative variability will consequently be higher. Increasing amounts of both PSA and C18, did on the other hand, generally result in lower responses (Figure $2 c$ and $2 d$ ), except for alpha-cypermethrin in the wheat extract and flusilazole in the oat extract. This same trend was observed when increasing levels of C18 were combined with a fixed level of $150 \mathrm{mg}$ PSA (Figure $2 e$ and $2 f$ ).

By taking both the effect on the intensity of the major matrix peak and the observed effects on the analytical responses into account, it is indicated that an optimal clean-up procedure for wheat employs $25 \mathrm{mg} \mathrm{PSA} / \mathrm{ml}$ extract and for oat $150 \mathrm{mg} \mathrm{PSA} / \mathrm{ml}$ extract. C18 does not add to the efficiency of the clean-up and in worst case it will compromise the recovery of the pesticides. Thus it varies how much matrix is co-extracted from the different types of grain. Before we consider to change our standard procedure for extraction of pesticides from oat we need however to gain more experience on how the higher amount of PSA affect the recoveries of pesticides not represented in this study. However, because several groups of pesticides were represented in the study we expect that recoveries from oat samples for the majority GC amenable pesticides will not be compromised by introducing dSPE with $150 \mathrm{mg} \mathrm{PSA} / \mathrm{ml}$ extract.

Though, as illustrated in Figure 3 the intensity of the major matrix peak (rt. about 13-22 min) may also vary for the same flour sample depending on the storage conditions. We have found that the major matrix peak is more intense in extract wheat, oat, rice and maize flour stored at room temperature than in flour stored at $20^{\circ} \mathrm{C}$. For this test the wheat flour had been stored at room temperature for 52 weeks, whereas the oat, rice and maize had been stored at room temperature for only four weeks. This increase in intensity may be attributed to a higher concentration of FFA in the cereal grains, which is known to increase with increasing storage time and moisture content [12]. A significant reduction of the major matrix peak in extracts of flour stored at room temperature may therefore require more extensive cleanup than freshly milled samples. Thus it may be more difficult to obtain reliable results when e.g. analyzing samples of flour, which have been stored for several months at room temperature, than when analyzing e.g. proficiency test material, which have been stored at lower temperatures and for shorter time after milling. In order to limit this non beneficial change of the matrix in samples of cereal these should be put in the freezer as soon as possible after sampling. 
Other co-extracted components, which is not ionizable and consequently does not reach the detector, may also affect the analytical response of the analytes, e.g. by forming active sites in the liner or column which bind the analyte and thereby compromise the analytical response [13]. Whether the occurrences of such components are also reduced by the suggested clean-up procedure needs to be studied.

\section{Conclusions}

Based on the present results, $25 \mathrm{mg}$ PSA provide efficient clean-up of wheat extracts, whereas $150 \mathrm{mg}$ PSA is needed for efficient clean-up of oat extracts. C18 did not have any significant effect on the intensity of the major matrix peak and generally no positive effect on the analytical responses. This is based on the present results which employed test materials which was stored in freezer $\left(-20^{\circ} \mathrm{C}\right)$ after milling. Further studies are however needed in order to evaluate whether $25 \mathrm{mg}$ and $150 \mathrm{mg} \mathrm{PSA}$ is also adequate for clean-up of other samples of wheat and oat which e.g. have been stored under less optimal conditions.

\section{Acknowledgements}

The current study, as well as the preparation of the test material for the proficiency test EUPT-C2, EUPT-C3, was performed in the framework of the EU Reference Laboratory for pesticide residues in cereals and feeding stuff financed by the European Commission.

\section{References}

[1] EN 15662 - Foods of Plant Origin - Determination of Pesticide Residues Using GC-MS and/or LCMS/MS Following Acetonitrile Extraction/Partitioning and Clean-up by Dispersive SPE (QuEChERS method)), (2008). Available at http://standards.cen.eu.

[2] S. Anastassiades, Michelangelo and Lehotay, Fast and Easy Multiresidue Method Employing Acetonitrile Extraction/Partitioning and "Dispersive Solid-Phase Extraction" for the Determination of Pesticide Residues in Produce, J. AOAC Int. 86 (2003) 412-431.

[3] P. Payá, M. Anastassiades, D. Mack, I. Sigalova, B. Tasdelen, J. Oliva, et al., Analysis of pesticide residues using the Quick Easy Cheap Effective Rugged and Safe (QuEChERS) pesticide multiresidue method in combination with gas and liquid chromatography and tandem mass spectrometric detection, Anal. Bioanal. Chem. 389 (2007) 1697-1714. doi:10.1007/s00216-007-16107.

[4] F.J. Schenck, S.J. Lehotay, Does further clean-up reduce the matrix enhancement effect in gas chromatographic analysis of pesticide residues in food?, J. Chromatogr. A. 868 (2000) 51-61. doi:10.1016/S0021-9673(99)01137-1.

[5] K. Mastovska, K.J. Dorweiler, S.J. Lehotay, J.S. Wegscheid, K. a Szpylka, Pesticide multiresidue analysis in cereal grains using modified QuEChERS method combined with automated direct sample introduction GC-TOFMS and UPLC-MS/MS techniques., J. Agric. Food Chem. 58 (2010) 5959-72. doi:10.1021/jf9029892.

[6] R.W. Welch, Fatty acid composition of grain from winter and spring sown oats, barley and wheat., J. Sci. Food Agric. 26 (1975) 429-435. doi:10.1002/jsfa.2740260408.

[7] S.J. Lehotay, K. Mastovská, S.J. Yun, Evaluation of two fast and easy methods for pesticide residue analysis in fatty food matrixes., J. AOAC Int. 88 (2005) 630-638.

[8] Y. Akiyama, T. Matsuoka, T. Mitsuhashi, Multi-residue screening method of acidic pesticides in agricultural products by liquid chromatography/time of flight mass spectrometry, J. Pestic. Sci. 34 (2009) 265-272. doi:10.1584/jpestics.G09-29. 
[9] M.E. Poulsen, H.B. Christensen, S.S. Herrmann, Proficiency test on incurred and spiked pesticide residues in cereals, Accredit. Qual. Assur. 14 (2009) 477-485. doi:10.1007/s00769-009-0555-2.

[10] M.E. Poulsen, M. Annastassiades, K. Hjorth, H.B.. Christensen, S.S.. Herrmann, P. Schreiter, Pesticide Residues in Cereals using Multi- and Single Residue Methods (EUPT-C3/SRM4), 2009. Available at www.eurl-pesticides.eu last accessed July 2015.

[11] X. Hou, M. Han, X. Dai, X. Yang, S. Yi, A multi-residue method for the determination of 124 pesticides in rice by modified QuEChERS extraction and gas chromatography-tandem mass spectrometry., Food Chem. 138 (2013) 1198-205. doi:10.1016/j.foodchem.2012.11.089.

[12] E.L. Molteberg, Effects of storage and heat processing on the content and composition of free fatty acids in oats., Cereal Chem. 72 (1995) $88-93$.

[13] J. Zrostlíková, J. Hajšlová, M. Godula, K. Maštovská, Performance of programmed temperature vaporizer, pulsed splitless and on-column injection techniques in analysis of pesticide residues in plant matrices, J. Chromatogr. A. 937 (2001) 73-86. doi:10.1016/S0021-9673(01)01308-5.

\section{Figure captions}

Figure 1. TIC chromatograms of wheat and oat extracts obtained after a range of different dSPE clean-up procedure employing PSA and C18. $1 \mathrm{a}$ and $1 \mathrm{~b}$ : experiment 1 wheat and oat; $1 \mathrm{c}$ and $1 \mathrm{~d}$ : experiment 2 wheat and oat; $1 \mathrm{e}$ and $1 \mathrm{f}$ : experiment 3 wheat and oat. The different colors represent the different clean-up procedures (Table 1); Red: I; Green: II; Purple III; Black IV; Brown VI; V is not illustrated.

Figure 2. Quantified levels after clean-up of wheat and oat extracts compared with the quantified levels in corresponding not cleaned-up extracts. The deviation is shown in percentage. The tested d-SPE procedures employed PSA and C18 at varying levels as followed: Experiment 1 with 0-200 mg PSA for wheat (2a) and oat (2b); Experiment 2 with 0-200 mg PSA and 0-200 mg C18 for wheat (2c) and oat (2d); Experiment 3 with $150 \mathrm{mg}$ PSA and $0-200 \mathrm{mg} \mathrm{C18}$ for wheat $(2 e)$ and oat (2f). Lines separate the pesticides into the groups of 1) conazoles, 2) organo phosphorous, 3) strobil ureas, 4) pyrethroids and 5) others.

Figure 3. Chromatograms different cereals stored at $-20^{\circ} \mathrm{C}(\mathrm{red})$ and the same flour stored at room temperature for 4 weeks (oat, rice and maize) and 52 weeks (wheat) (green). 


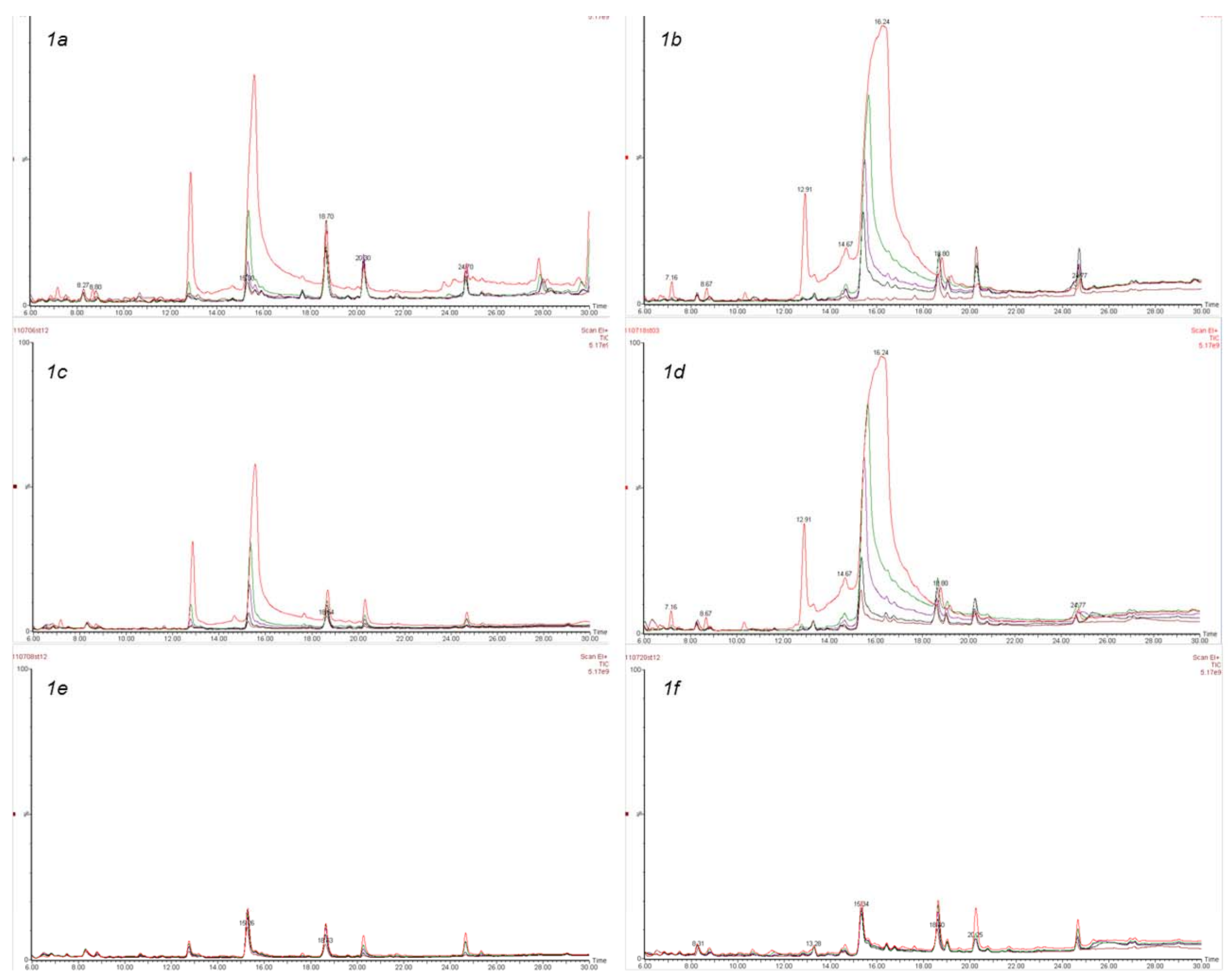




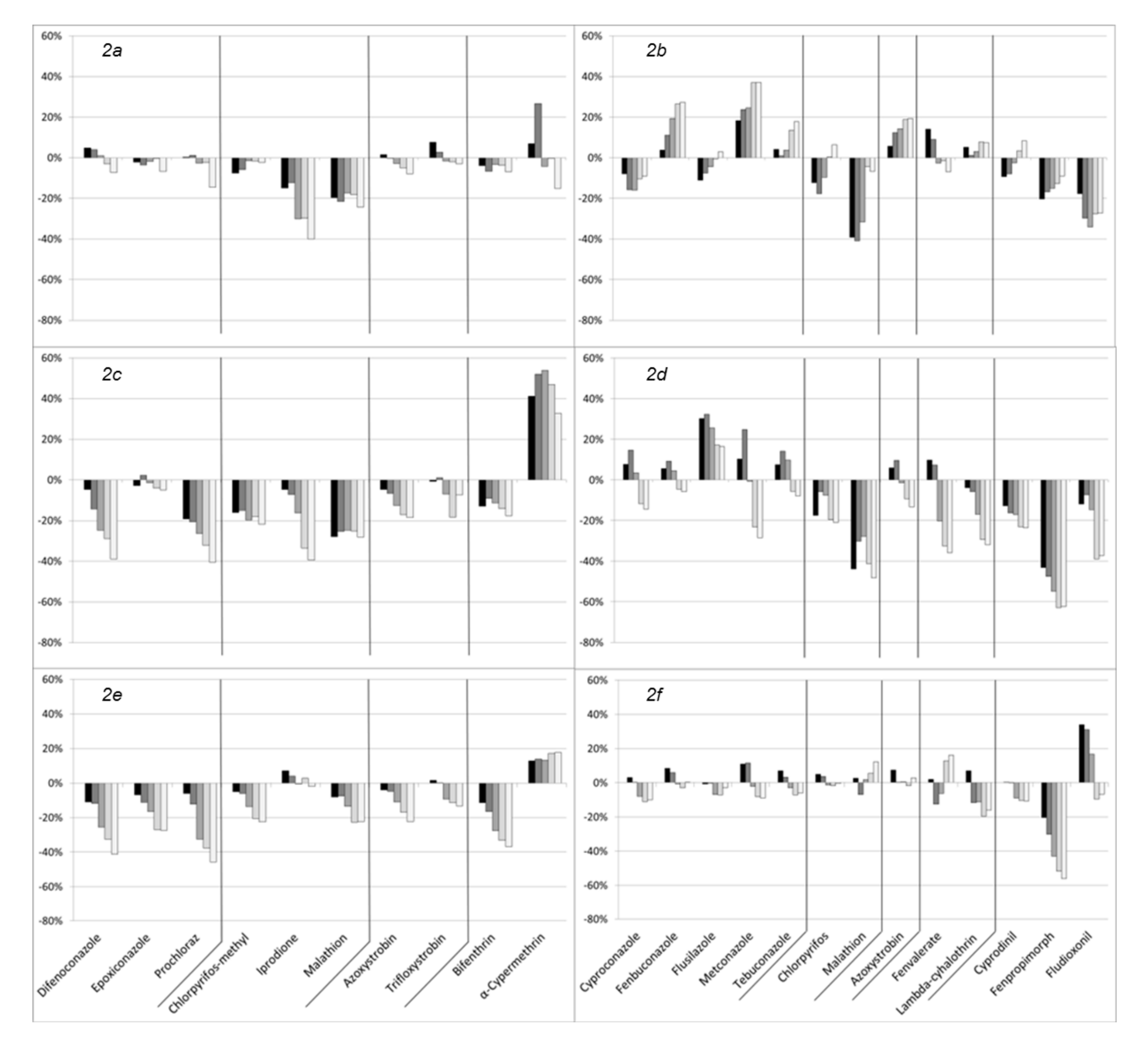


Table 1. Overview of the three experimental setups outlining the amount of PSA and C18 added to the extracts during dSPE clean- up. All experiment were performed as double determination on EUPT-C2 wheat and EUPT-C3 oat

\begin{tabular}{|c|c|c|c|c|c|c|c|}
\hline \multirow[t]{2}{*}{$\begin{array}{l}\text { Test } \\
\text { materials }\end{array}$} & \multirow[t]{2}{*}{$\begin{array}{l}\text { Clean-up } \\
\text { procedure }\end{array}$} & \multicolumn{2}{|c|}{$\begin{array}{c}\text { Experiment } 1 \\
\text { Increasing amount } \\
\text { of PSA, } \\
\mathrm{mg} / \mathrm{ml} \text { extract }\end{array}$} & \multicolumn{2}{|c|}{$\begin{array}{c}\text { Experiment } 2 \\
\text { Increasing amount of } \\
\text { PSA and C18, } \\
\mathrm{mg} / \mathrm{ml} \mathrm{extract}\end{array}$} & \multicolumn{2}{|c|}{$\begin{array}{c}\text { Experiment } 3 \\
\text { Fixed amount of PSA } \\
\text { and increasing amount } \\
\text { of C18 } \\
\mathrm{mg} / \mathrm{ml} \text { extract }\end{array}$} \\
\hline & & PSA & $\mathrm{C} 18$ & PSA & C18 & PSA & $\mathrm{C} 18$ \\
\hline EUPT-C2 & 1 & 0 & 0 & 0 & 0 & 150 & 0 \\
\hline and & II & 25 & 0 & 25 & 25 & 150 & 25 \\
\hline \multirow[t]{4}{*}{ EUPT-C3 } & III & 50 & 0 & 50 & 50 & 150 & 50 \\
\hline & IV & 100 & 0 & 100 & 100 & 150 & 100 \\
\hline & V & 150 & 0 & 150 & 150 & 150 & 150 \\
\hline & VI & 200 & 0 & 200 & 200 & 150 & 200 \\
\hline
\end{tabular}


Table 2. GC-MS/MS conditions including Retention times (rt.), transitions for quantifier and qualifier and collision energy (CE) as well as assigned values for the pesticides in test material EUPT-C2 and EUPT-C3.

\begin{tabular}{|c|c|c|c|c|c|c|c|}
\hline \multirow[b]{2}{*}{ Pesticide } & \multicolumn{5}{|c|}{ GC-MS/MS conditions } & \multicolumn{2}{|c|}{$\begin{array}{c}\text { Assigned value in } \\
\text { test material } \\
(\mathrm{mg} / \mathrm{kg})\end{array}$} \\
\hline & rt. & $\begin{array}{l}\text { Transition } 1 \\
\text { (quantifier) } \\
\end{array}$ & $\mathrm{CE}$ & $\begin{array}{c}\text { Transition } 2 \\
\text { (qualifier) }\end{array}$ & $\mathrm{CE}$ & $\begin{array}{l}\begin{array}{l}\text { EUPT-C2 } \\
\text { (wheat) }\end{array} \\
\end{array}$ & $\begin{array}{c}\text { EUPT-C3 } \\
\text { (oat) }\end{array}$ \\
\hline Alpha-cypermethrin & 25.69 & $163>127$ & 10 & $181>152$ & 20 & 0.079 & \\
\hline Azoxystrobin & 29.06 & $344>329$ & 15 & $388>360$ & 15 & $0.239^{1)}$ & 0.175 \\
\hline Bifenthrin & 20.46 & $181>166$ & 10 & $165>115$ & 20 & 0.087 & \\
\hline Chlorpyrifos & 13.32 & $197>169$ & 10 & $314>258$ & 12 & & 1.04 \\
\hline Chlorpyrifos-methyl & 12.06 & $286>93$ & 20 & $125>79$ & 5 & 0.130 & \\
\hline Cyproconazole & 16.87 & $222>125$ & 15 & $139>111$ & 15 & & 0.453 \\
\hline Cyprodinil & 14.05 & $226>225$ & 15 & $223>208$ & 15 & & 0.076 \\
\hline Difenoconazole & $27.79+27.92$ & $323>265$ & 15 & $325>267$ & 15 & $0.169^{11}$ & \\
\hline Epoxiconazole & 19.63 & $192>138$ & 10 & $206>165$ & 5 & 0.176 & \\
\hline Fenbuconazole & 24.68 & $198>129$ & 10 & $129>102$ & 15 & & 0.508 \\
\hline Fenpropimorph & 13.29 & $303>128$ & 5 & $117>115$ & 10 & & 0.121 \\
\hline Fenvalerate & $27.06+27.45$ & $167>125$ & 10 & $125>99$ & 10 & & 0.097 \\
\hline Fludioxonil & 16.09 & $248>127$ & 20 & $154>127$ & 5 & & 0.078 \\
\hline Flusilazole & 16.48 & $314>233$ & 20 & $206>137$ & 20 & & 0.728 \\
\hline Iprodione & 20.03 & $314>245$ & 10 & $216>187$ & 5 & 0.289 & \\
\hline Lambda-cyhalothrin & $21.96+22.33$ & $197>141$ & 10 & $208>181$ & 10 & & 0.050 \\
\hline Malathion & 13.02 & $173>99$ & 10 & $173>127$ & 5 & $0.168^{1)}$ & $0.011^{2)}$ \\
\hline Metconazole & 20.84 & $125>89$ & 10 & $127>89$ & 10 & & 0.478 \\
\hline Prochloraz & 24.11 & $180>138$ & 10 & $310>268$ & 5 & $0.239^{1)}$ & \\
\hline Tebuconazole & 19.08 & $250>125$ & 15 & $125>89$ & 10 & & 1.23 \\
\hline Trifloxystrobin & 18.73 & $222>190$ & 5 & $186>145$ & 10 & 0.439 & \\
\hline
\end{tabular}

1) Pesticides spiked in laboratory

2) Residue was too low to establish an assigned value, so the value is the median of the reported results 